\title{
A Parallel Ugi Reaction at Students Laboratories in the Ural and Moscow
}

\author{
M. A. Mironov ${ }^{a}$ and E. V. Babaev ${ }^{b}$ \\ ${ }^{a}$ Eltsin Ural State Technical University (USTU), u. Mira 19, Yekaterinburg, 620002 Russia \\ e-mail:mironov@mail.ustu.ru \\ ${ }^{b}$ Lomonosov Moscow State University, Vorob'evy Gory 1, Moscow, 119991 Russia \\ e-mail:babaev@org.chem.msu.ru
}

Received July 10, 2009

\begin{abstract}
A four-component Ugi reaction was adapted for students education. To this end, a series of almost odorless aromatic isonitriles with donor substituents was reacted with a specific carboxylic acid, phthaloyl glycine, to obtain poorly soluble (although nicely crystallized) products. The process was performed and compared in two versions by using (1) a standard centrifuge for parallel separation of precipitates and (2) parallel filtration with SynCore apparatus. It is shown for a broad series of aliphatic ketones and benzyl amines that the yields are satisfactory and the products require no further purification.
\end{abstract}

DOI: $10.1134 / \mathrm{S} 1070363210120303$

In 2000-2001, at the Ural State Technical University, Yekaterinburg, there was developed a "Combinatorial Chemistry" laboratory training course for third year students specializing in biotechnology. The aim of this laboratory course was to develop practical skills in the field of parallel synthesis and consolidate the lecture material on combinatorial chemistry. Taking into account the basic student' training level, we had to find a simple and illustrative example of the parallel organic synthesis technology. The Ugi reaction is an ideal decision, since it allows compound libraries to be obtained without a complex equipment and hardly accessible reagents. The reagents were chosen so that to obtain precipitates which could be separated in parallel by centrifuging. It should be mentioned that the Ugi reaction is also used at students laboratories at some foreign universities (for example, at the Munich Technical University).

The practical work at the USTU was envisioned for four lessons: an introductory workshop and three practical lessons. For fourth year students, an extended program comprising five practical lessons requiring a higher level basic training was suggested. In the first part of this paper we present a series of procedures and instructions which can help one to include the Ugi reaction in any laboratory training in combinatorial chemistry.
Almost simultaneously, special laboratory training in combinatorial chemistry for fifth year students was initiated at the Lomonosov MSU. The Moscow group first experimented with training tasks on solid-phase synthesis $[1,2]$, and the task in parallel liquid-phase synthesis involved reductive amination [3]. After the MSU had acquired instrumentation for parallel filtration, a necessity arose to find an illustrative training task. After the heads of these training courses (the authors of the present paper) had met face-to-face and exchanged experience, the Moscow group attempted to adapt the procedure developed at the USTU for use for the Syncore reactor (I. Dlinnykh, E. Belykh, and V. Alifanov were involved in this work in different times). In the second part of this paper we present the results of this experiment. In our opinion, the experience in such collaboration may be of interest for other universities.

\section{Basic Information on the Ugi Reaction}

We consider it useful, to start with a workshop on the methodology of parallel synthesis and application of multicomponent reactions (MCRs). The term MCR relates to reactions that occur on direct mixing of three and more reagents, and the final structure includes fragments of all starting reagents. 
(a)

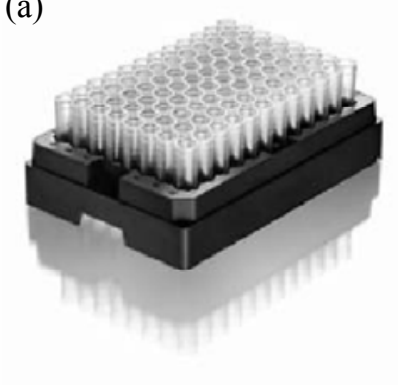

(b)

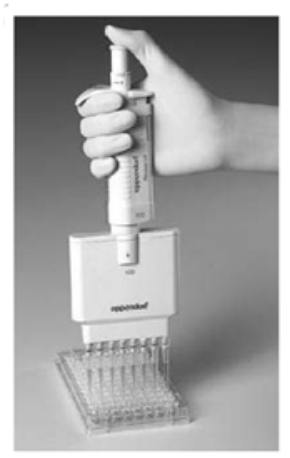

Fig. 1. Equipment for the implementation of the Ugi reaction: (a) plastic plates with tubes and (b) multichannel pipette.

There are different classifications of MCR, depending on their mechanistic features [4]. The main advantage of such reactions is that they allow one to obtain a great number of derivatives in one stage from simple and accessible starting materials. It should be noted that MCRs are widely used for solving diverse practical tasks in the search for new biologically active compounds, catalysts, new materials, etc. One of the most popular of reactions of this type is the fourcomponent Ugi condensation discovered in 1960. The reaction involves isocyanides, carbonyl compounds, amines, and organic/inorganic acids.

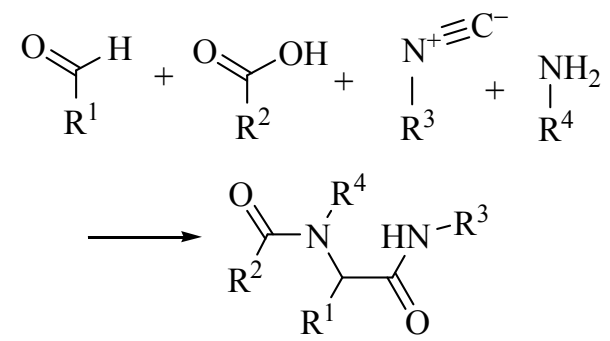

The Ugi condensation provides a great number of derivatives $\left(10^{4}\right)$, features a considerable flexibility (presently several tens of its versions are known,

which open up the way to various scaffold structures) and mild reaction conditions (room temperature), which is ideally suited for automated synthesis. All these advantages attracted attention of researchers working in combinatorial chemistry, as well as pharmaceutical companies searching for new biologically active compounds. At present abundant published material on the reaction itself and practically valuable compounds obtained by this reaction is available. In preparation to the workshop we recommend the reviews [5-7].

\section{Experience in Accomplishing the Ugi Reaction at Students Laboratories at the USTU}

As the training task for students we use one of the simplest versions of the Ugi reactions, specifically, preparation of amino acids by mixing an aromatic isocyanide, aliphatic ketones, benzylamines, and phthalyl glycine (Scheme 1).

This choice is not occasional, it allows one to perform a practical work with minimal preparation, provides excellently reproducible results, and requires no expensive or dangerous reagents. With phthalyl glycine, poorly soluble derivatives which readily crystallize and can be isolated in parallel in the framework of one laboratory work are available. In their turn, aromatic isocyanides with polar groups are low-volatile and have almost no characteristic odor. Benzylamines and aliphatic ketones whose function is to provide various side-chain substituents are accessible and fairly cheap reagents. It should be noted that the described laboratory course was developed for engineering students and envisioned no subsequent testing of the resulting compounds. Therefore, the scaffold in Scheme 1 does not have biologically active analogs. For students of other specializations (for example, medicinal chemistry) one can use a different target compounds, according to [6]. The procedures described below all remain therewith unchanged.

Scheme 1.

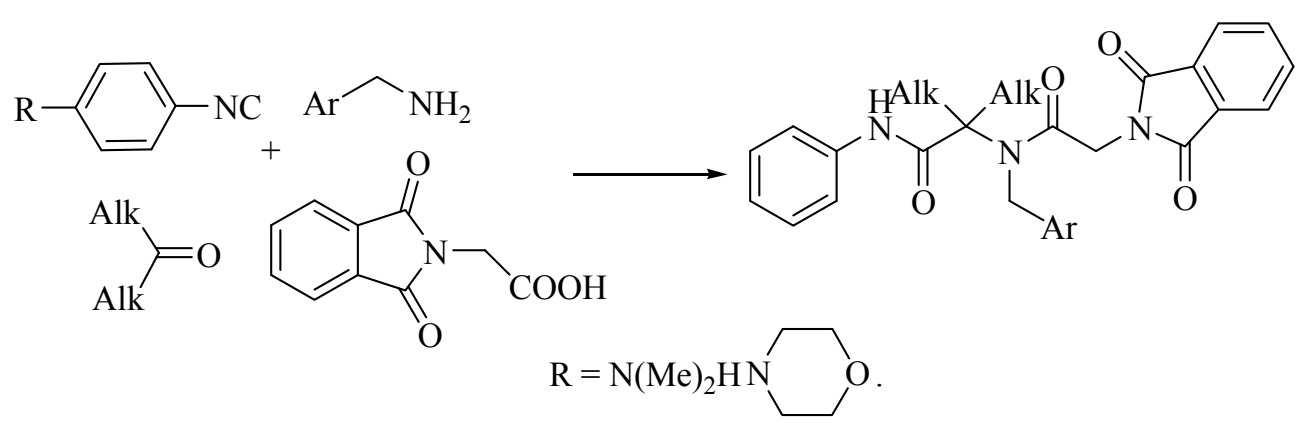


Scheme 2.<smiles>CC(=O)CC(C)C1CCC(=O)C1</smiles>

A

B

C

D<smiles>NCc1ccccc1</smiles>

1<smiles>COc1ccc(CN)cc1</smiles>

3<smiles>NCc1ccc(F)cc1</smiles>

4<smiles>NCc1ccc(Cl)cc1</smiles>

5

Reagents loaded in all tubes<smiles>N#Cc1ccc(N2CCOCC2)cc1</smiles>

I<smiles>O=C(O)CN1C(=O)c2ccccc2C1=O</smiles>

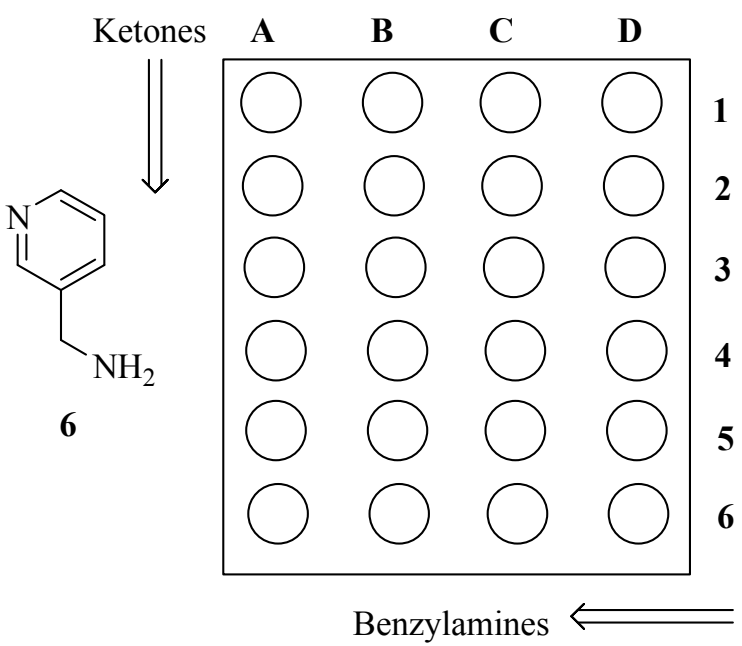

Practical skills acquired during the work. Students use equipment for parallel synthesis: single- or multichannel micropipettes, reaction plates, and shaker. A short introductory lesson is required if student have never dealt with such equipment. The acquired skills may prove useful at microscale divisions of pharmaceutical and chemical companies, as well as at any analytical laboratory.

Materials and instruments. For laboratory work the following equipment should be prepared:

(1) Plastic $8 \times 12$ plates with separate tubes (each $1 \mathrm{ml}$ in volume), like Micronic or Falcon plates (Fig. 1a). Well plates used in analytical chemistry are less convenient.

(2) Fixed-volume 50- or $100-\mu 1$ micropipettes (both single- and multichannel, Fig. 1b), as well as tip sets for them.

(3) Shaker (almost any model can be used).

(4) Laboratory centrifuge with a swing-bucket rotor. Centrifuges with an angle rotor are less convenient.

(5) Set for thin-layer chromatography or analytical chromatograph.

(6) Glassware for starting solutions, balances, and other laboratory equipment.
Reagents. For charging one plate one needs about $500 \mathrm{mg}$ of each reagent.

(1) Phthalyl glycine is prepared by fusing equimolar amounts of phthalic anhydride and glycine in a porcelain dish to obtain a homogeneous mass which is then crystallized from aqueous alcohol, $\mathrm{mp} 198^{\circ} \mathrm{C}$ [8].

(2) Isocyanide, for example, 4-(dimethylamino)phenyl isocyanide, is prepared by the procedure in [9]. A suspension of $3.2 \mathrm{mmol}$ of 4-(dimethylamino)nitrosobenzene in $40 \mathrm{ml}$ of ethanol is added to a solution of $3.2 \mathrm{mmol}$ of 3-phenylisoxazol-5-one (can be readily synthesized from benzoylacetic ester and hydroxylamine) in $20 \mathrm{ml}$ of ethanol. The mixture is heated on a water bath for $15 \mathrm{~min}$, cooled, and the precipitate is filtered off. The product is heated in toluene at $90^{\circ} \mathrm{C}$ for $30 \mathrm{~h}$, toluene is removed by distillation, and the residue is sublimed in a vacuum at $75^{\circ} \mathrm{C}$. Total yield $65-70 \%, \mathrm{mp} 61^{\circ} \mathrm{C}$.

This reagent can be replaced by other aromatic isocyanides: 4-morpholinophenyl isocyanide or 2,4dimethoxyphenyl isocyanide. The advantage of these reagents is their high activity and lack of the characteristic isocyanide odor.

(3) Substituted benzylamines (Scheme 2).

(4) Ketones (Scheme 2). 
Table 1. Yields of target products (\%), obtained by a group of students in 2004 (loading by Scheme 2)

\begin{tabular}{c|c|c|c|c|c|c}
\hline \multirow{2}{*}{ Ketones } & \multicolumn{6}{|c}{ Benzylamines } \\
\cline { 2 - 7 } & $\mathbf{1}$ & $\mathbf{2}$ & $\mathbf{3}$ & $\mathbf{4}$ & $\mathbf{5}$ & $\mathbf{6}$ \\
\hline A & 49 & 48 & 41 & 55 & 62 & 46 \\
B & 54 & 67 & 60 & 65 & 73 & 51 \\
C & 76 & 81 & 66 & 68 & 77 & 58 \\
D & 78 & 75 & 62 & 69 & 71 & 53 \\
\hline
\end{tabular}

(5) Methanol (if methanol is prohibited for use, it can be replaced by a $4: 1$ acetonitrile-water mixture).

\section{PRACTICAL IMPLEMENTATION OF THE WORK}

\section{Lesson 1. Reagent loading.}

Each student or a group of students obtain a hard copy of the database corresponding to the library to be obtained. Before starting experimental work, students should write down equations of the reactions leading to the target structure. At the colloquium, if it precedes the work, detailed analysis of the mechanism of the Ugi reaction can be given. Then students form in themselves a reagent loading table in which isocyanide and acid are invariable and benzylamines and ketons are variable parameters. Therewith, benzylamines are labeled with digits and ketones, with letters (Scheme 2).

The next step is to prepare solutions of the starting compounds. The concentration of all solutions is

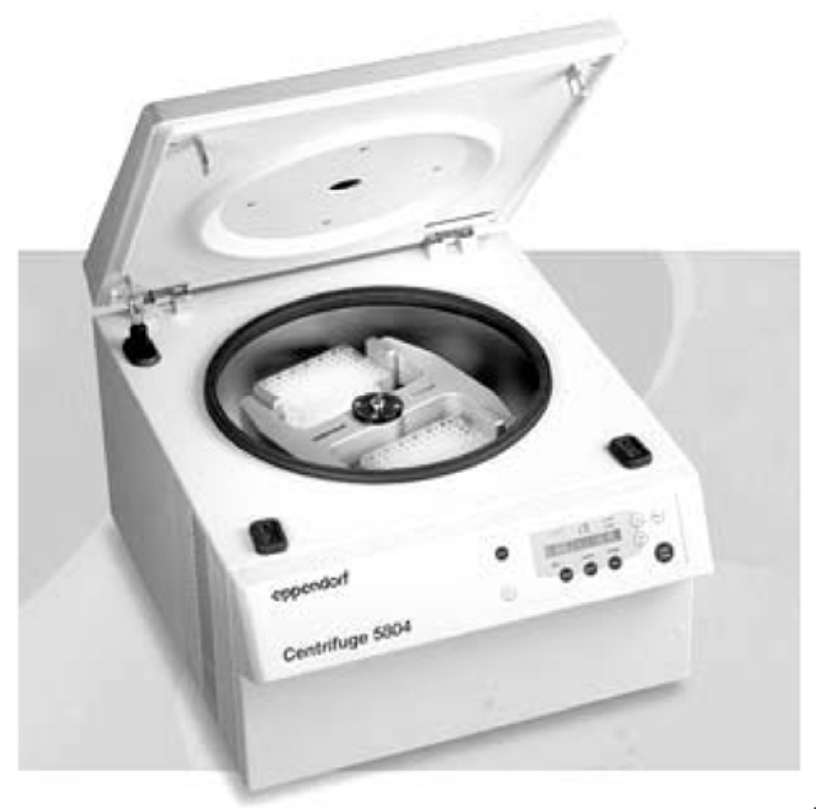

Fig. 2. Centrifuge with a rotor for microplates.
$1 \mathrm{mmol} \mathrm{m} l^{-1}$ in methanol. A total of 12 solutions are prepared: 1 with isocyanide, 1 with phthalyl glycine, 4 with ketones, and 6 with benzyl amines. The choice of ketones and benzylamines depends on the potential of each concrete laboratory. According to our experience, virtually any set allows amino acid derivatives to be prepared with good yields by the below-described procedures. As a recommendation, we provide the set shown in Scheme 2.

Further students start to load all starting reagents, by $0.1 \mathrm{mmol}$ each, into plates by means of $100-\mu \mathrm{l}(50 \mu \mathrm{l}$, if the concentration of all solutions is $\left.2 \mathrm{mmol} \mathrm{ml}^{-1}\right)$. The following loading sequence is strictly followed: (1) benzylamines, (2) ketones, (3) isocyanide, (4) phthalyl glycine.

It should be noted that only part of the plate $(4 \times 6)$ is loaded, and, therewith, loading is better started from the left upper angle (tube A1). All manipulations with solutions are performed under a hood. If students have never dealt with micropipettes, a preliminary practical lesson is recommended. It is useful to record the time of loading with multichannel pipettes to estimate the time gain compared with traditional methods.

When loading is complete, plates are covered, transferred to a shaker, and agitate at room temperature for $20 \mathrm{~min}$. Students should visually estimate the efficiency of mixing.

\section{Lesson 2. Product isolation.}

In the case of correct loading, all target compounds precipitate. Depending on a concrete reagent set, the reaction time varies from 4 to $6 \mathrm{~h}$. Therefore, the second practical lesson is recommended to be held on the next day. (Note that prolonged keeping results in decreased product yields).

Before the lesson, students should be instructed in how to operate with the centrifuge and to discuss its operation principles.

Then students prepare a washing liquid (ethanolwater, 3:1).

Further actions depend on the type of the centrifuge, and the best centrifuge here is a centrifuge equipped with a special rotor for microplates. However, almost any model with the rotation speed $3000-4000 \mathrm{rpm}$ (Fig. 2) is suitable. Wet precipitates in the plate are placed in an oven $\left(<50^{\circ} \mathrm{C}\right)$ and dried for 5-6 h. 


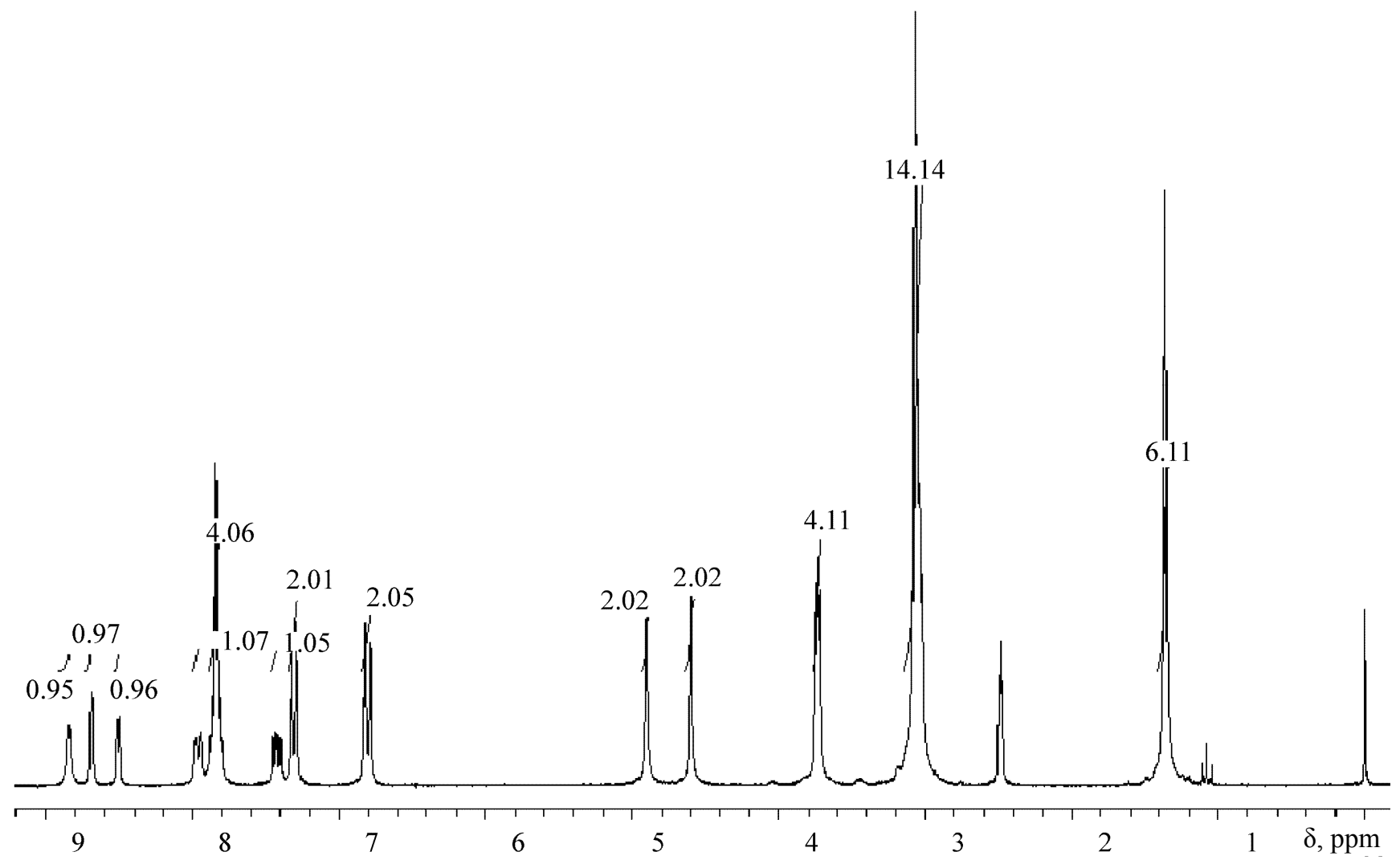

Fig. 3. ${ }^{1} \mathrm{H}$ NMR spectrum of compound $\mathbf{A 6}$.

\section{Lesson 3. Product analysis.}

If all the above-described operations are fulfilled properly, the purity of products is higher than $90 \%$. Since the reaction proceeds sufficiently completely in all cases, the yields of products depend, first of all, on their solubility in the washing liquid. The parallel liquid-phase technology presented in our example envisions the same is procedures for isolation of all target compounds, which makes possible high isolation rates but does not ensure high yields (Table 1).

Students weigh the precipitates and determine the yields of the target compounds, which should fall in the range $40-80 \%$.

Then student analyze the target products by TLC (an analytical chromatograph is also suitable). For TLC, the samples are dissolved in chloroform and chromatographed in $\mathrm{CHCl}_{3} /$ ethanol (95:5). The chromatograms are observed under a UV light, $R_{\mathrm{f}}$ values are recorded. Reaction completeness is estimated by the presence or absence of the isocyanide spot. The samples synthesized by a previous group of students can be used as references. A more detailed analysis of admixtures is performed by ${ }^{1} \mathrm{H}$ NMR (Figs. 3 and 4).

As seen from Table 1, lower yields are observed for compounds containing polar groups like pyridin-3-yl or 4-methoxyphenyl. It was found that the target compounds are partly lost with the washing liquid. The water/ethanol ratio in the washing liquid affects the yields and purity of the resulting products. For better results this ratio can be varied to obtain the highest yield for each series.

${ }^{1} \mathrm{H}$ NMR spectra were measured for the compound obtained by students. No further purification was performed.

Compound A6. mp $275-276^{\circ} \mathrm{C}$, purity $>95 \%$. The spectrum (Fig. 3) shows signals of ethanol, implying incomplete drying. The spectrum of $\mathbf{A 6}$ is typical for the entire series of compounds. The side-group signals are readily identifiable: 2 methylene groups at $4.5-$ $5.0 \mathrm{ppm}, 2$ methyl groups at $1.0-1.5 \mathrm{ppm}$, and four pyridyl signals at $7.4-8.8 \mathrm{ppm}$. The phthalyl fragment signals are observed at $7.8-8.0 \mathrm{ppm}$ as a four-proton 


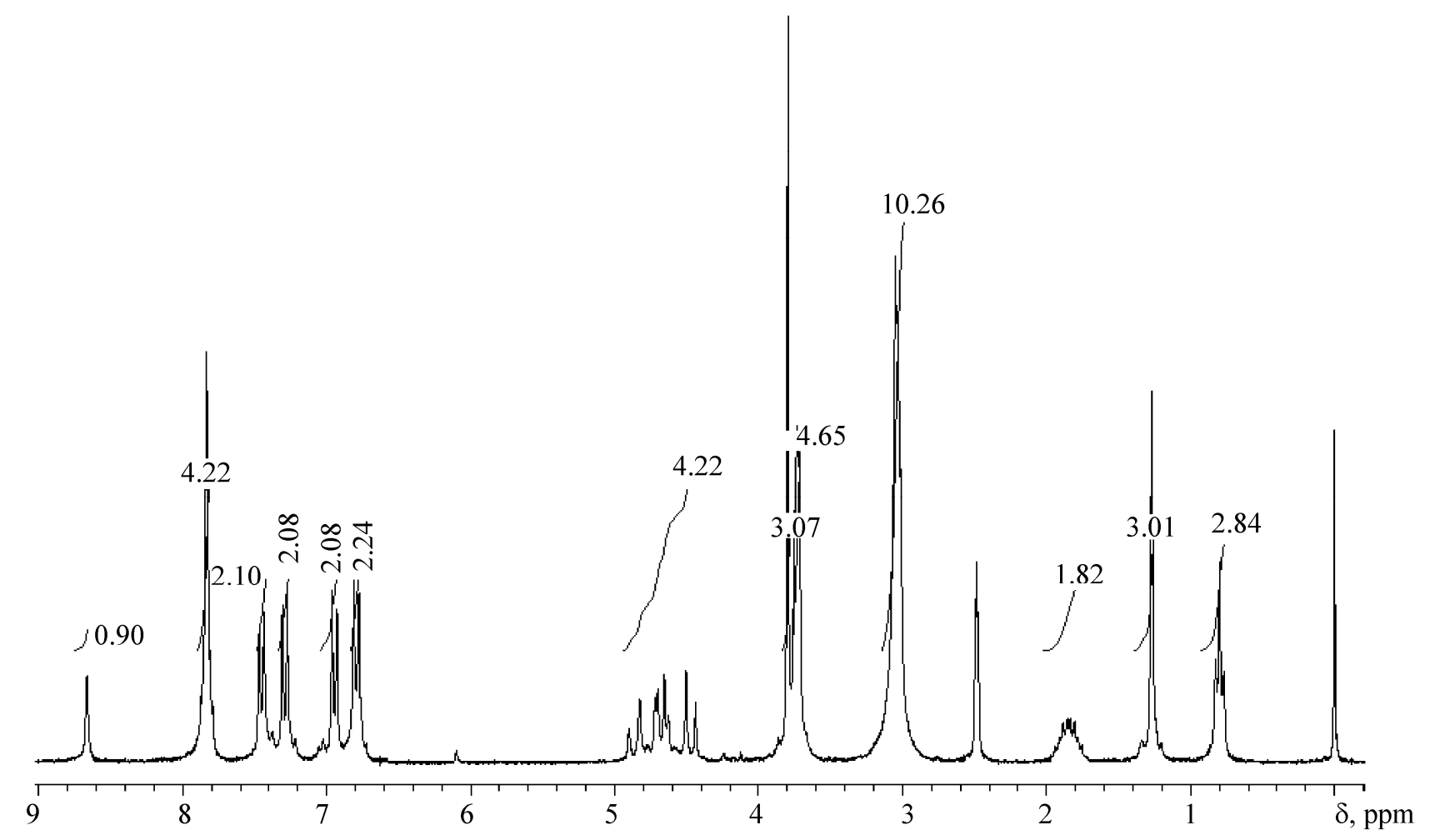

Fig. 4. ${ }^{1} \mathrm{H}$ NMR spectrum of compound $\mathbf{B 3}$.

multiplet. The phenylmorpholine fragment gives a characteristic 4-signal set ( 2 signals of the aromatic moiety at 6.6-7.4 ppm and 2 signals of the aliphatic moiety at 3.0-3.7 ppm), one of which overlaps with the water signal. The NH proton appears as a downfield signal at 8.8-9.2 ppm.

Compound B3. mp $280-281^{\circ} \mathrm{C}$, purity $\sim 90 \%$. The admixtures (see the ${ }^{1} \mathrm{H}$ NMR spectrum in Fig. 4) here are the starting compounds: isocyanide and phthalyl glycine. The signals are assigned by analogy with the above compound. The difference consists in that the methylene proton signals are nonequivalent, which is characteristic of derivatives of unsymmetrical ketones.

\section{Variant of Implementing the Task at the MSU}

The given task was first suggested to students of the Chemical Department of the MSU at the special laboratory course in combinatorial chemistry in 2006. The work was performed in SynCore apparatus for parallel synthesis.
Reagents, materials, and instruments. Phthalyl glycine, 4-(dimethylamino)phenyl isocyanide, a series of the simplest ketones:<smiles>CCC(C)=O</smiles>

A B<smiles>O=C1CCCC1</smiles>

C<smiles>O=C1CCCCC1</smiles>

D
A series of benzylamines:

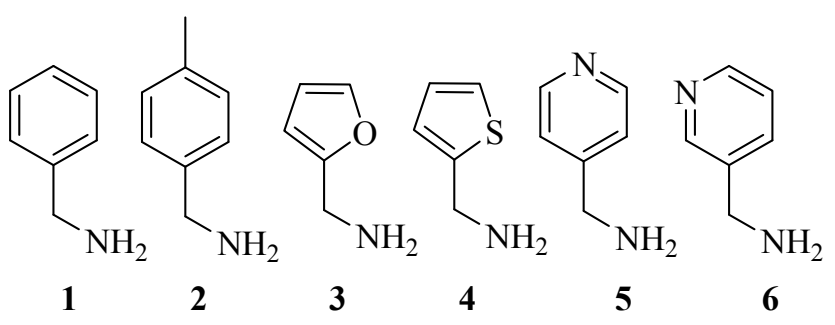

organic solvents, and SynCore apparatus. 


\section{PRACTICAL IMPLEMENTATION OF THE TASK}

Students get a variant with the task to synthesize one compound by a multicomponent Ugi reaction. All starting reagents are loaded in equimolar amounts (1.0 mmol).

\section{Lesson 1. Reagent loading.}

A special tube for SynCore is provided by a label corresponding to the variant obtained. For example, B-3 (B is ketone and $\mathbf{3}$ is benzylamine). Each tube is loaded, in strict sequence, with $1 \mathrm{ml}$ of an alcohol solution of amine, $1 \mathrm{ml}$ of a ketone solution, $2 \mathrm{ml}$ of an isonitrile solution (in a hood), and $1 \mathrm{ml}$ of a phthalyl glycine solution. The tube is then placed into the reaction module of SynCore and agitated for $4 \mathrm{~h}$.

\section{Lesson 2. Product isolation.}

The precipitates are filtered off in the filtration block of SynCore (Fig. 5a) and washed two times with alcohol/water (3:1) in the parallel mode (Fig. 5b), after which the tubes with precipitates were placed into a vacuum drying oven.

Unlike the reductive amination task [3], where on filtering on Syncore we collected mother liquors, in the given task we collect and separate precipitates remaining in the reaction vessels. On filtering (Fig. 5a), a stream of nitrogen is fed into all the 24 tubes. As a result, the mother liquor is forced through 24 plastic tubings. These tubings are then replaced with hermetic seals, and the system is attached, by a common plastic tubing, to a flask with the washing liquid (Fig. 5b). To wash all the 24 precipitates simultaneously, a rubber tubing is attached to vacuum, and the washing liquid from the flask is admitted uniformly into all the 24 tubes. In necessary, the shaker is turned on, and the precipitates are suspended. The filtration procedure is repeated the required number of times.

Lesson 3. Assessment of the yield and purity of products.

A clean vial is provided with a label with the task variant and weighed. The precipitate is then transferred into this vial, the latter is weighed again, and the yield is estimated. The purity of the resulting compound is determined by TLC, and smaples for spectral analysis are taken.

The percent yields of the Ugi reaction are listed in Table 2, and an example spectrum of one the products
Table 2. Yields of target products in the Ugi reaction (\%)

\begin{tabular}{c|c|c|c|c|c|c}
\hline \multirow{2}{*}{ Ketones } & \multicolumn{6}{|c}{ Amines } \\
\cline { 2 - 7 } & $\mathbf{1}$ & $\mathbf{2}$ & $\mathbf{3}$ & $\mathbf{4}$ & $\mathbf{5}$ & $\mathbf{6}$ \\
\hline \multirow{2}{*}{ A } & 40 & 11 & 32 & 42 & 50 & 23 \\
B & $\mathrm{a}$ & 10 & $\mathrm{a}$ & 6 & 11 & 20 \\
C & 38 & 10 & 43 & 41 & 28 & 32 \\
D & 25 & - & 54 & 38 & 20 & 9 \\
\hline
\end{tabular}

${ }^{\mathrm{a}}$ The reaction was not performed.

is presented in Fig. 6. Comparison with the data in Table 1 shows that the product yields are slightly lower and the product purities are roughly the same as in the original USTU version.

(a)

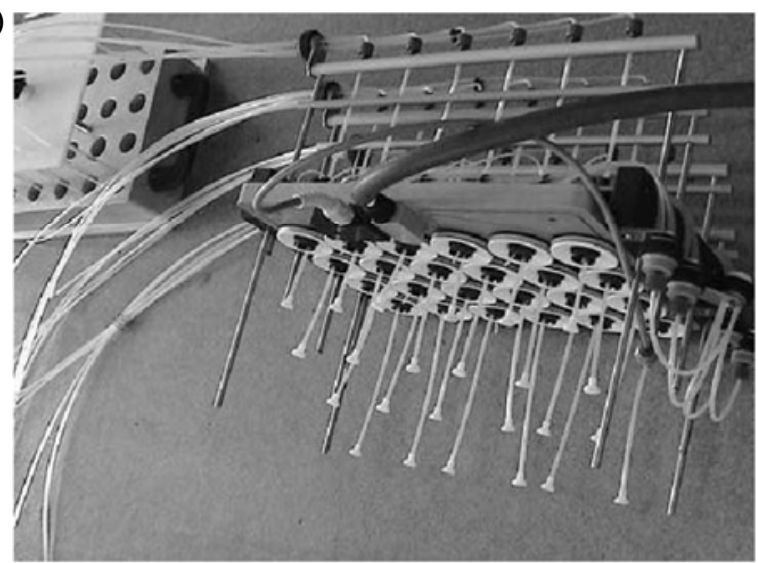

(b)

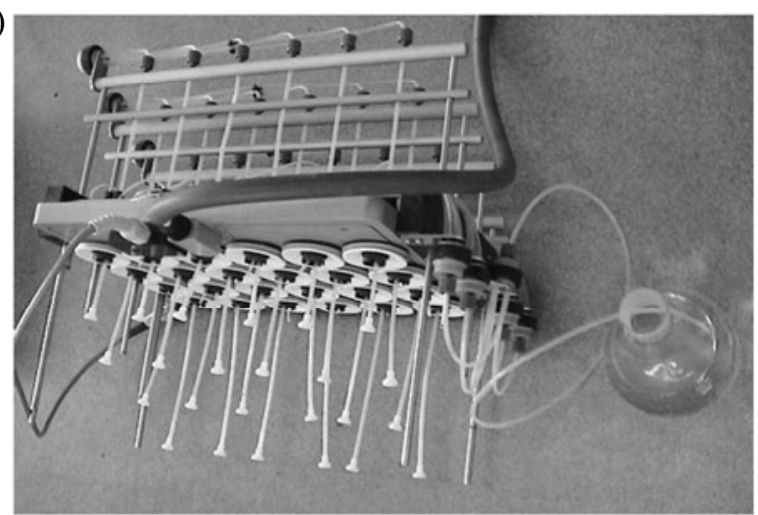

Fig. 5. Attachment for SynCore apparatus for parallel filtration of 24 suspensions: (a) for filtration, 24 plastic tubings are attached to the left part of the attachment for forcing over the mother liquors; and (b) for washing, a bottle with a washing liquid is attached to the right part of the attachment. 


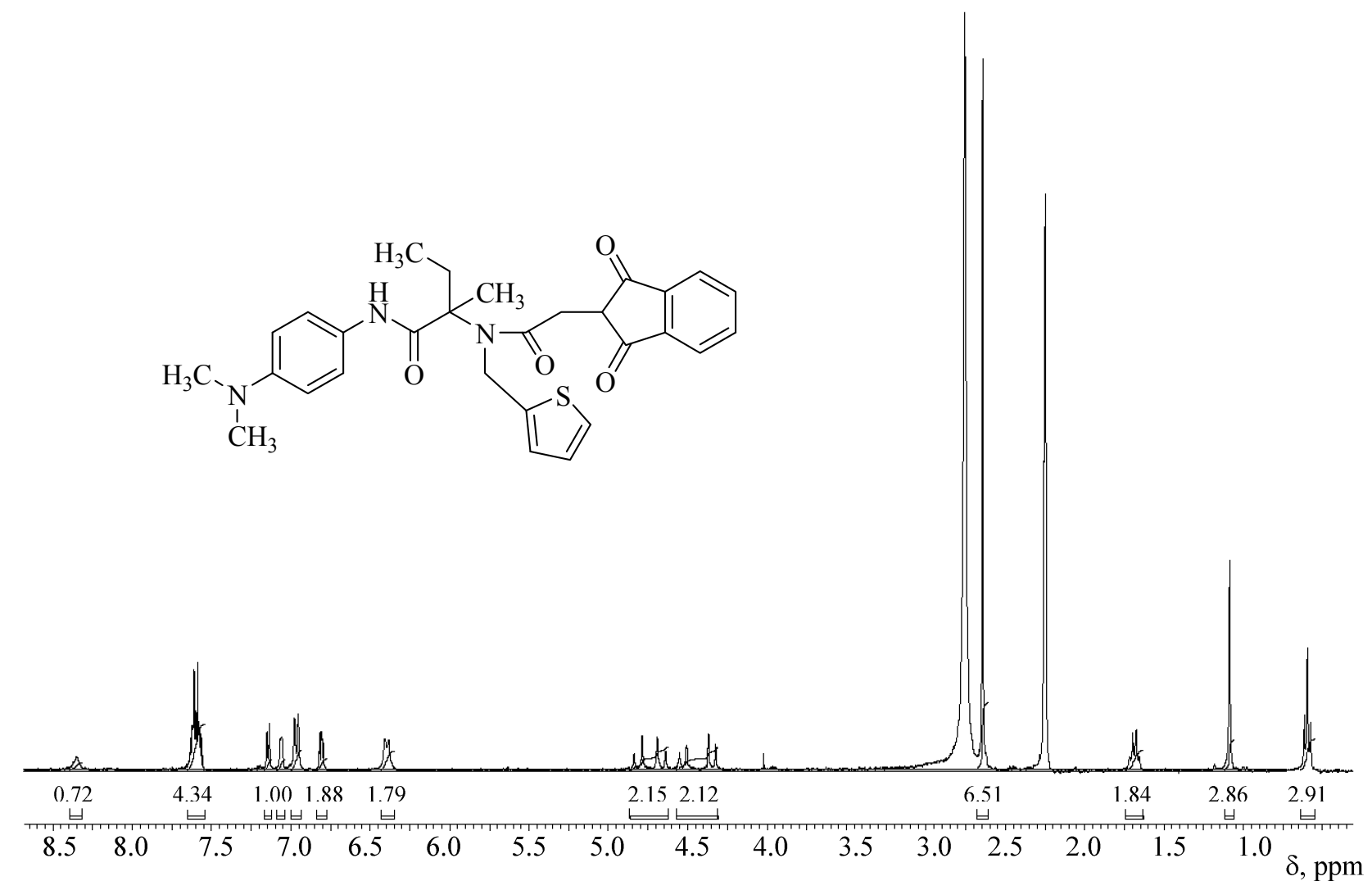

Fig. 6. ${ }^{1} \mathrm{H}$ NMR spectrum of one of the obtained products.

\section{REFERENCES}

1. Babaev, E.V. and Ermolat'ev, D.S., Ross. Khim. Zh. (Zh. Ross. Khim. O-va im. D.I. Mendeleeva), 2009, vol. 53, no. 5, pp. 42-56.

2. Babaev, E.V., Ibid., pp. 57-72.

3. Ivanova, N.V., Tkach, N.V., Belykh, E.N., Dlinnykh, I.V., and Babaev, E.V., Ibid., pp. 105-115.

4. Multicomponent Reactions, Zhu, J. and Bienayme, H., Eds., Weinheim: Wiley-VCH, 2005.
5. Ugi, I. and Dömling, A., Angew. Chem. Int. Ed., 2000, vol. 39, pp. 3168-3210.

6. Dömling, A., Chem. Rev., 2006, vol. 106, pp. 17-89.

7. Mironov, M.A., Ross. Khim. Zh. (Zh. Ross. Khim. O-va im. D.I. Mendeleeva), 2009, vol. 53, no. 5, pp. 116-132.

8. Greenstein, J.P. and Wintz, M., Chemistry of the Amino Acids, New York: Wiley, 1961.

9. Wentrup, C., Stutz, U., and Wollweber, H-J., Angew. Chem., 1978, vol. 90, pp. 731-732. 